\title{
NO LUGAR ERRADO, NA HORA ERRADA: ICNOFÓSSEIS DE METAZOÁRIOS NO PALEOPROTEROZÓICO DE MINAS GERAIS?
}

\author{
LEONARDO MORATO \\ CPGGeo, IG, UFRGS, Av. Bento Gonçalves 9500, 91501-970, Cx. P. 15001, Porto Alegre, RS, Brasil. gepaleo@yahoo.com.br \\ LUEDSON GUIMARÃES MANDUCA \\ luedson.manduca@gmail.com \\ ISMAR DE SOUZA CARVALHO \\ Departamento de Geologia, IGEO, UFRJ, Cidade Universitária, Ilha do Fundão, 21940-940, Rio de Janeiro, RJ, Brasil. \\ ismar@geologia.ufrj.br
}

\author{
CARLOS ALBERTO ROSIÈRE \& RICARDO DINIZ DA COSTA \\ Departamento de Geologia, IGC, UFMG, Av. Antônio Carlos 6627, 31270-901, Belo Horizonte, MG, Brasil. \\ crosiere@gmail.com,biduufmg@gmail.com
}

\begin{abstract}
RESUMO - Duas estruturas sedimentares comparáveis a icnofósseis de metazoários foram descritas em rochas do Paleoproterozóico da Formação Cercadinho, Supergrupo Minas do Quadrilátero Ferrífero, Estado de Minas Gerais. As estruturas são perturbações parabólicas na laminação, perpendiculares ao acamamento de metarenitos com estratificações plano-paralelas a cruzadas tangenciais e acanaladas. A primeira, uma escavação semelhante a Skolithos ou Arenicolites, atinge 1,4 cm de largura e cerca de 4,5 cm de altura, com paredes nítidas e laminação interna desordenada; a segunda é comparável a um icnito de escape, com até $1,7 \mathrm{~cm}$ de largura e $6,7 \mathrm{~cm}$ de altura. A idade da Formação Cercadinho é bem restringida, entre 2,1 e 2,4 Ga, por uma série de dados geocronológicos e estratigráficos. A hipótese de que tais estruturas tenham sido produzidas por metazoários durante o Paleoproterozóico é incongruente com os registros fósseis mais antigos desse grupo. Outra possibilidade seria a de que essas estruturas não tenham origem orgânica e os processos que as formaram ainda sejam desconhecidos. Entretanto, experimentos preliminares, efetuados em laboratório, revelam ser difícil a geração de feições semelhantes por processos abióticos.
\end{abstract}

Palavras-chave: Icnofósseis, metazoários, biotas pré-cambrianas, Quadrilátero Ferrífero.

ABSTRACT - WRONG TIME, WRONG PLACE: METAZOAN ICHNOFOSSILS IN THE PALAEOPROTEROZOIC OF MINAS GERAIS STATE? Two sedimentary structures comparable to metazoan ichnofossils are described in Palaeoproterozoic rocks of the Cercadinho Formation, Minas Supergroup of the Quadrilátero Ferrífero region, Minas Gerais state, Brazil. The structures are parabolic perturbations in the lamination, perpendicular to the bedding of metasandstones with tabular, tangential and parallel cross-laminations. The first one, similar to an Arenicolites-type burrowing, reaches $1.4 \mathrm{~cm}$ in width and about $4.5 \mathrm{~cm}$ in high, with sharp walls and disordered internal lamination; the second is comparable to an escape ichnite, up to $1.7 \mathrm{~cm}$ in width and $6.7 \mathrm{~cm}$ in high. The age of the Cercadinho Formation is well constrained between 2.1 and $2.4 \mathrm{Ga}$ by a series of geochronological and stratigraphical data. A hypothesis that these structures are in fact of metazoan affinities in Palaeoproterozoic rocks is incongruent with the oldest records of metazoan fossils. Another possibility, more likely, is that the structures are not organic-related, and its genesis is so far unknown. Preliminary laboratory experiments, however, advocate the difficulty to generate similar structures by abiotic processes.

Key words: Trace fossils, metazoan, Precambrian biotas, Quadrilátero Ferrífero.

\section{INTRODUÇÃO}

Os icnofósseis possuem diversas aplicações. Dependendo do icnotáxon envolvido, podem ser indicadores paleoclimáticos, de ambientes de sedimentação ou de taxas de depo- sição, podem servir de referência de base e topo de camadas, além de delimitar paleopavimentos. Podem também ser registros válidos da presença de um determinado táxon (geralmente apenas em uma categoria superior, acima do nível de gênero) e de seus hábitos, e eventualmente serem utilizados 
como guias para algumas amplitudes temporais. Icnofósseis começam a ser abundantes no final do Proterozóico, quando surgem organismos complexos em profusão, capazes de retrabalhar ativamente os sedimentos.

Nesse estudo são descritas estruturas sedimentares comparáveis a icnitos de metazoários, em rochas paleoproterozóicas da Formação Cercadinho (Grupo Piracicaba, Supergrupo Minas) do Quadrilátero Ferrífero, Estado de Minas Gerais. Entretanto, a ocorrência de icnofósseis em rochas tão antigas é muito improvável, devido à ausência de evidências de vida de metazoários nesse tempo (ver, e.g., Fedonkin, 1990; Crimes, 1994; Narbonne, 2005; Peterson \& Butterfield, 2005), o que abre um debate sobre o significado e gênese das estruturas observadas. Portanto, além de descrevê-las, o objetivo deste trabalho é discutir, a partir de diferentes cenários hipotéticos, a natureza de tais estruturas.

\section{CONTEXTO GEOLÓGICO}

O acesso ao afloramento que contém as estruturas se dá próximo à localidade de Fecho do Funil, entre as cidades de Mário Campos e Brumadinho, a menos de $42 \mathrm{~km}$ a sudoeste da capital do Estado (Figura 1). O afloramento se localiza nas coordenadas UTM Zona 23K 582.972E, 7.777.731N (datum Córrego Alegre), ao longo de um gasoduto da Petrobrás, na chamada serra dos Franceses. Essa feição fisiográfica se encontra no setor intermediário do segmento ocidental da serra do Curral, a oeste da junção com o sinclinal da Moeda e a leste de sua sobreposição com o rio Paraopeba, na porção noroeste do Quadrilátero Ferrífero.

A estratigrafia do Quadrilátero Ferrífero foi inicialmente estabelecida por Dorr (1969), podendo ser subdividida em cinco unidades litoestratigráficas: terrenos granito-gnáissicos, Supergrupo Rio das Velhas, Supergrupo Minas, intrusivas pós-Minas e Grupo Itacolomi (Figura 2).

Tanto os terrenos granito-gnáissicos como as rochas do Supergrupo Rio das Velhas podem servir de embasamento para as unidades do Supergrupo Minas. Os terrenos granito-gnáissicos compõem vários complexos de rochas cristalinas arqueanas, normalmente englobando gnaisses tonalíticos a granodioríticos migmatitizados. Terrenos greenstone arqueanos associados a rochas metassedimentares compõem o Supergrupo Rio das Velhas, subdividido nos grupos Nova Lima, na base, e Maquiné, no topo. O primeiro compreende seqüências metavulcânicas, com basaltos e komatiitos, além de formações ferríferas bandadas do tipo Algoma, metapelitos e carbonatos, enquanto que o segundo corresponde a uma unidade clástica, onde predominam rochas quartzíticas.

A estruturação do Quadrilátero Ferrífero é definida pelo arranjo de sinclinais orientados segundo as direções NESW, N-S e E-W onde afloram os sedimentos plataformais do Supergrupo Minas, determinando sua forma aproximadamente quadrangular. Essa seqüência se destaca no relevo, sendo mais resistente ao intemperismo que as rochas dos terrenos granito-greenstone subjacentes.

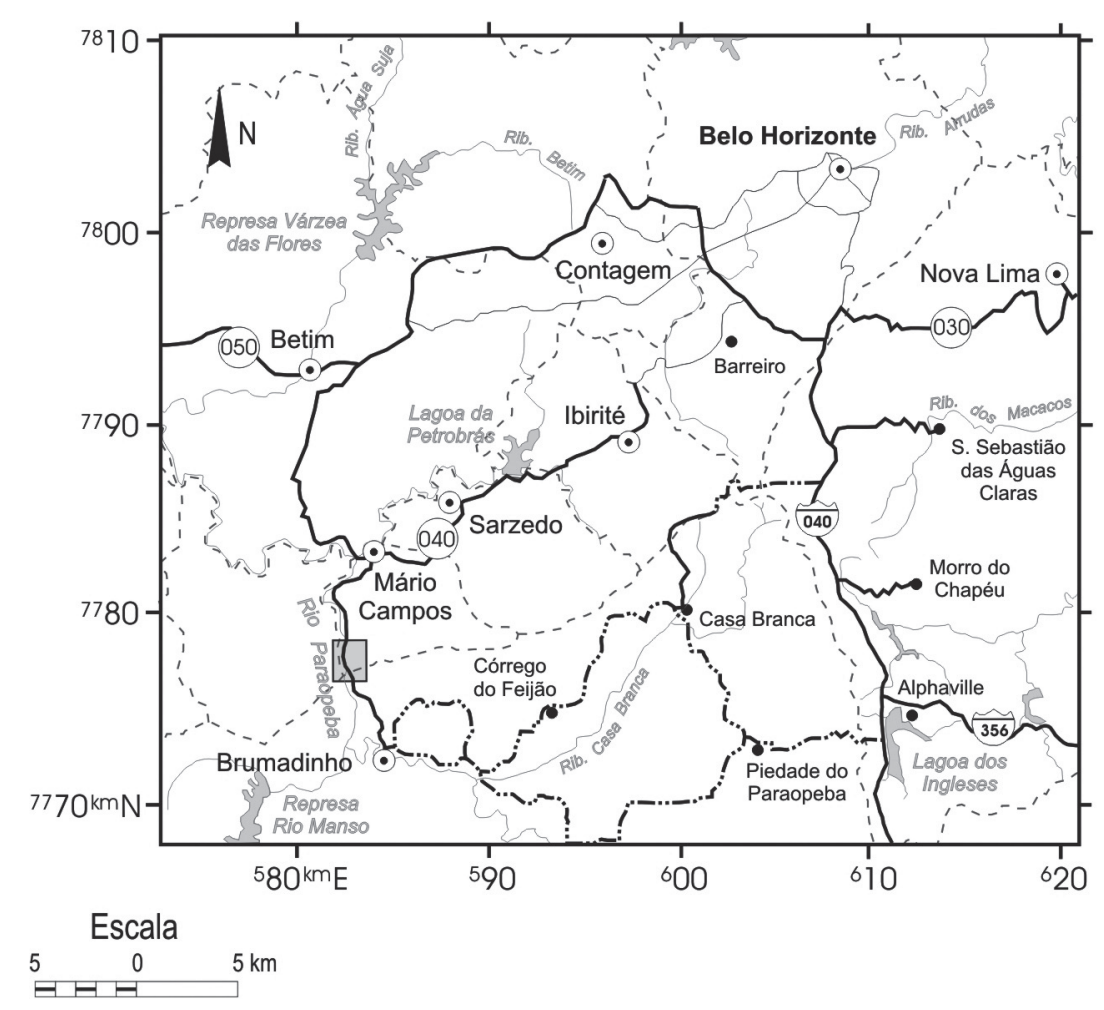

LOCALIZAÇÃO DO MAPA

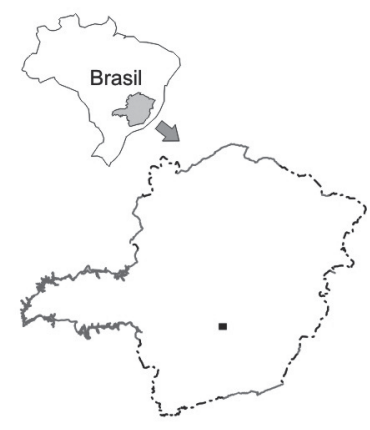

CONVENÇÕES

- Distrito ou povoado

- Cidade

Rodovia federal

Rodovia estadual

Via urbana

Rodovia pavimentada

Rodovia em

revestimento primário

Represas e drenagens

,- - Limite municipal

Área de estudo (Figura 3)

Figura 1. Mapa de localização e acesso, indicando a posição do mapa geológico da Figura 3.

Figure 1. Situation map, showing the location of the geological map in Figure 3. 
Dorr (1969) subdividiu o Supergrupo Minas nos grupos Caraça, Itabira e Piracicaba. As unidades basais compreendem conglomerados e arenitos fluviais, passando a pelitos de ambiente marinho raso, que compõem, respectivamente, as formações Moeda e Batatal, do Grupo Caraça. O Grupo Itabira apresenta na base formações ferríferas bandadas do tipo Lago Superior, além de corpos de hematita compacta e filitos, compondo a Formação Cauê, seguindo-se por uma seqüência predominantemente carbonática, depositada em águas rasas, que determina a Formação Gandarela, cujo membro intermediário apresenta estromatólitos em hemisferóides lateralmente ligados e oncólitos. O contato superior com o Grupo Piracicaba se dá por uma discordância angular e erosiva, podendo ocasionar a total supressão da Formação Gandarela em algumas localidades.

O Grupo Piracicaba é subdividido em quatro formações. A unidade basal é a Formação Cercadinho, composta por metarenitos e quartzitos ferruginosos, intercalados a filitos sericíticos. A Formação Fecho do Funil apresenta mármores dolomíticos com vestígios de estruturas estromatolíticas, além de filitos quartzosos e dolomíticos. Seguem-se duas forma-
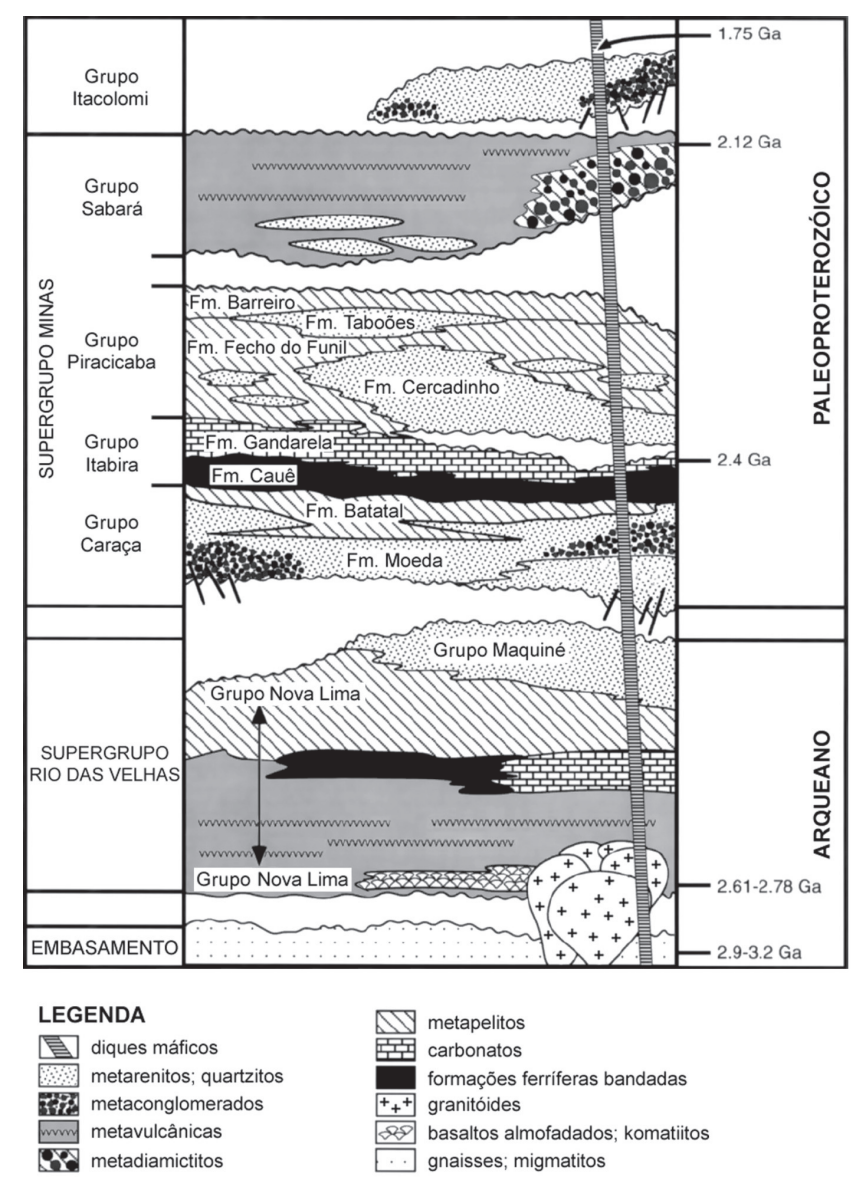

Figura 2. Litoestratigrafia do Quadrilátero Ferrífero (porção oriental, à direita; porção ocidental, à esquerda) e algumas idades radiométricas disponíveis (modificado de Alkmin \& Marshak, 1998).

Figure 2. Lithostratigraphy of Quadrilátero Ferrífero (eastern part at right, western part at left), and some available radiometric ages (modified of Alkmin \& Marshak, 1998). ções de pouca espessura, denominadas Taboões, com predomínio de ortoquartzitos, e Barreiro, com filitos grafitosos.

Sobreposto a essas unidades ocorre ainda o Grupo Sabará, definido como formação do Grupo Piracicaba por Dorr (1969), e composto por unidades de origem vulcânica e vulcanoclástica de posição estratigráfica ainda incerta. Metassedimentos de composição arcosiana compõem o Grupo Itacolomi, considerado uma seqüência molássica, embora sua ocorrência, predominantemente na forma de blocos alóctones, dificulta o estabelecimento de seu posicionamento estratigráfico.

Rochas intrusivas, incluindo pequenos veios pegmatíticos e diques básicos, podem cortar parte ou toda a seqüência. Alguns dos plútons granitóides que cortam os complexos granito-gnáissicos podem ser também posteriores à deposição do Supergrupo Minas (Alkmin \& Marshak, 1998). Silva et al. (2002) interpretam parte das rochas previamente referidas como de terrenos granito-gnáissicos do embasamento ao sul e leste do Quadrilátero Ferrífero como produtos de magmatismos préa sincolisionais na estruturação da região.

As rochas do Quadrilátero Ferrífero apresentam metamorfismo de grau xisto-verde baixo a anfibolítico, tendo sido afetadas ao menos pelos eventos transamazônico $(\sim 2,1 \mathrm{Ga})$ e brasiliano ( 0,6 Ga). Diversos autores (e.g., Romano, 1989; Babinski et al., 1995; Machado et al., 1996; Alkmim \& Marshak, 1998; Silva et al., 2002) indicam que o primeiro evento teria tido papel principal no metamorfismo regional, porém Caby (2000) sugere a formação de associações minerais sinmetamórficas exclusivamente durante o evento brasiliano.

\section{Geologia da serra dos Franceses}

Na região da serra dos Franceses, o embasamento é representado pelas rochas do Gnaisse Souza Noschese, que fazem parte do Complexo Bonfim. Esse complexo compreende gnaisses e granito-gnaisses ortoderivados de composição granítica a granodiorítica, cortados por diques pegmatíticos e aplitos deformados. O contato com as rochas supracrustais do Supergrupo Minas é tectônico, com a presença de zonas de cisalhamento.

O mapeamento da região (Figura 3) revelou que o Supergrupo Minas está representado por quase toda a sequiência, composto pelos grupos Caraça, Itabira, Piracicaba e Sabará. Acima desses, o Grupo Itacolomi está ausente.

Caracterizado como uma sequiência clástica progradante, o Grupo Caraça apresenta as formações Moeda e Batatal, embora ambas aflorem de forma descontínua. A sequiência filítica de topo é praticamente individualizada apenas por seus produtos de alteração e formas de relevo associadas. No Grupo Itabira, quartzoitabiritos e itabiritos anfibolíticos (alterados) da Formação Cauê afloram razoavelmente, marcando a crista da serra. A ocorrência da Formação Gandarela é atestada por afloramentos de rochas dolomíticas, de cor arroxeada a esverdeada, embora seu contato com a Formação Cauê não seja evidente: a gradação entre essas unidades pode se dar em uma ampla faixa. $O$ contato foi determinado pelo desaparecimento dos quartzoitabiritos e pelo rebaixamento do relevo, provavelmente relacionado à alteração dos itabiritos dolomíticos da Formação Gandarela. 
Essa situação também obscurece as relações de contato da Formação Gandarela com as rochas da Formação Cercadinho, base do Grupo Piracicaba, embora a passagem de uma unidade para a outra fique clara na variação do relevo. As rochas mais competentes da Formação Cercadinho formam uma nova escarpa de serra. Situação semelhante ocorre em diversas áreas do Quadrilátero Ferrífero (Dorr, 1969), mas de forma geral é possível inferir que ocorra uma discordância erosiva entre as duas unidades.

A Formação Cercadinho apresenta metarenitos, quartzitos e filitos ferruginosos. C. M. Noce (com. pess.) indica também a ocorrência de rochas carbonáticas nessa Formação, no segmento ocidental da serra do Curral, podendo representar atividade orgânica. Os metarenitos apresentam bandamento composicional com níveis quartzosos e hematíticos, bem como variação granulométrica, podendo também apresentar estruturas sedimentares preservadas, como estratificações planoparalelas e cruzadas tangenciais e acanaladas. A laminação é marcada por níveis ferruginosos finos. Os quartzitos são geralmente bem selecionados, de granulação fina a média, com clastos arredondados de quartzo, magnetita e hematita. Já os filitos são principalmente sericíticos, de cor esverdeada, aflorando em vários locais, pouco alterado, em camadas pouco espessas, intercaladas aos níveis arenosos.

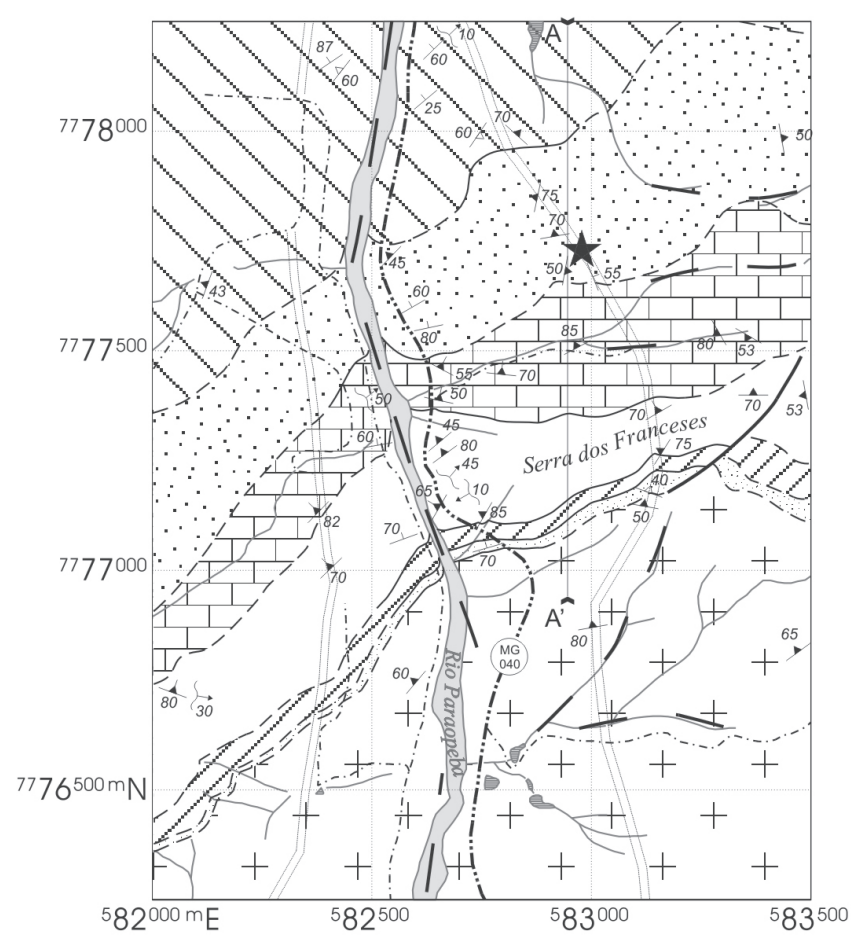

DECLINAÇÃO MAGNÉTICA EM 2006

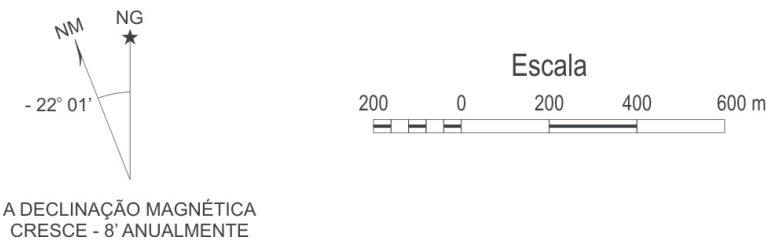

$\mathrm{Na}$ área de estudo, as unidades superiores à Formação Cercadinho se encontram bastante alteradas, ou se apresentam aflorantes de forma restrita. A Formação Fecho do Funil apresenta metassiltitos carbonáticos bandados e filitos dolomíticos de cor cinza, muitas vezes alterados a solos avermelhados em terrenos rebaixados. São encontrados afloramentos restritos de dolomitos maciços, extremamente recristalizados, de coloração arroxeada a esverdeada. A Formação Taboões tem pouca espessura, não se destacando no relevo; ela é composta predominantemente por quartzitos finos, puros, equigranulares, de coloração cinza-oliva a branca. Segue-se a Formação Barreiro, com filitos grafitosos de coloração cinza-escuro, devido à presença de material carbonoso.

O Grupo Sabará ocorre indiviso, com litótipos diversos. Ele apresenta quartzitos, grauvacas líticas com fragmentos de filitos, quartzitos ferruginosos, filitos e xistos, extremamente intemperizados.

\section{DESCRIÇÃO DAS ESTRUTURAS}

Durante os trabalhos de mapeamento geológico da serra dos Franceses, duas estruturas parabólicas de dimensões centimétricas foram observadas em níveis distintos, separadas por poucos metros uma da outra, em um mesmo afloramento
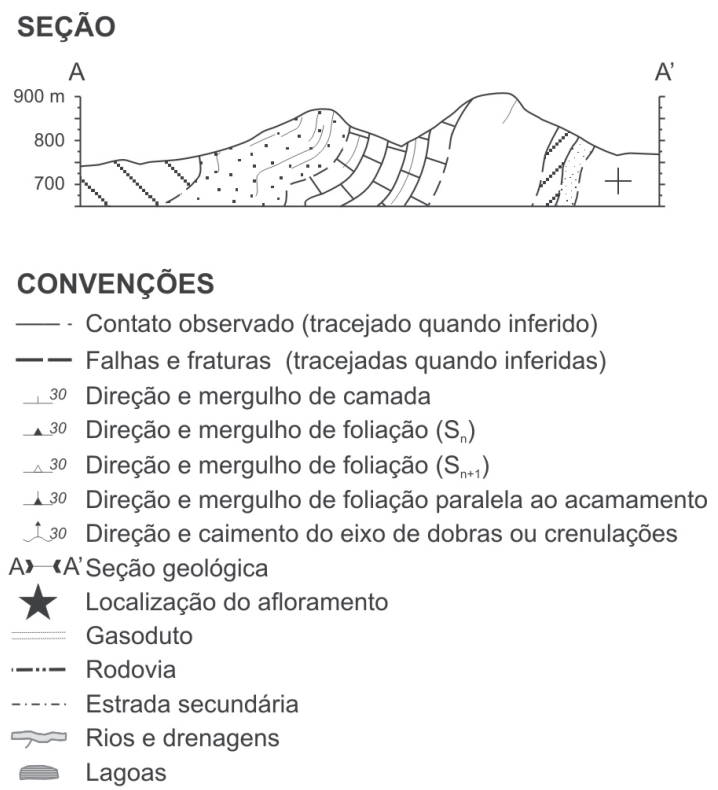

\section{UNIDADES LITOESTRATIGRÁFICAS}

Grupo Piracicaba

Formação Fecho do Funil
$\because$ Formação Cercadinho
Grupo Itabira
Formação Gandarela
Frupo Carmação Cauê
Formação Batatal
Complexo Bonfim
Comão Moeda
+ Gnaisse Souza Noschese

Figura 3. Mapa geológico local e seção N-S da serra dos Franceses.

Figure 3. Local geological map and N-S section through the Franceses Hills. 
de metarenitos da Formação Cercadinho. Certamente as estruturas não são mais jovens que a rocha, um problema que foi notado em alguns casos de icnofósseis propostos para rochas muito antigas (e.g., Cloud et al., 1980). Elas não foram coletadas para permitir observações posteriores, in loco.

A primeira estrutura (Figura 4) apresenta-se como uma escavação perpendicular em relação ao plano de acamamento. Suas paredes externas são bem delimitadas, verticais e subparalelas no topo, convergindo-se na base, gerando um contorno parabólico. Não se observam ramificações, nem estruturas equivalentes a spreite em seu interior: a laminação interna é geralmente desordenada, a não ser por algumas lâminas tênues próximas à base, que acompanham o contorno externo, sugerindo um tubo em forma de $\mathrm{U}$ de preenchimento passivo. Toda a estrutura atinge até $1,4 \mathrm{~cm}$ de largura e cerca de $4,5 \mathrm{~cm}$ de altura, mas o diâmetro dos tubos individuais seria próximo dos $4 \mathrm{~mm}$, medido no vértice da estrutura, embora por efeito de corte os tubos verticais não pareçam ter muito mais que $2 \mathrm{~mm}$ de largura. Essa descrição enquadrase, em diversos aspectos, na diagnose do icnogênero Arenicolites Salter, 1857, considerado como estruturas biogênicas de habitação ou alimentação, embora as dimensões reportadas sejam menores que as de diversos espécimes fanerozóicos reconhecidos (ver Abreu et al., 1993; Netto, 2002; Fernandes et al., 2002; McIlroy \& Garton, 1994; Fernandes \& Carvalho, 2006).

A segunda estrutura (Figura 5) é uma escavação vertical retilínea, talvez cilíndrica, perpendicular ao plano de acamamento, sem lineações de bordo ou ramificações. Atinge até $1,7 \mathrm{~cm}$ de largura e $6,7 \mathrm{~cm}$ de altura, sendo registrada como uma série de perturbações parabólicas em forma de chevron na laminação, com concavidades voltadas para cima, de amplitude cada vez menor em direção ascendente, e apresentam continuidade com a estratificação ao redor. As estruturas representam colapso de material sedimentar durante a deposição, e são compatíveis com estruturas de fuga de organismos (ver Abreu et al., 1993; Bromley, 1996; Fernandes et al., 2002), preservadas como endichnia (Martinsson, 1970). Os meniscos na laminação mostram espaçamento irregular, porém acompanham a distribuição das camadas. Mesmo que essa irregularidade algumas vezes possa refletir uma modificação comportamental de um organismo, provavelmente resultante de uma reação à não homogeneidade do sedimento (Fürsich, 1974), esse não parece ser o caso. A redução da amplitude das concavidades na laminação, visível na parte superior das estruturas descritas, parece indicar também uma redução do espaço disponível para o material sedimentar posterior, ou taxas de sedimentação mais rápidas, que podem estar associadas também à ausência de um organismo no final da sedimentação.

Abaixo de ambas as estruturas, ocorrem ainda outras estruturas de revolvimento na laminação, em níveis mais cimentados por óxidos de ferro. Em seção, elas se apresentam como concavidades delimitadas por lâminas ferruginosas mais espessas, como um revestimento peletoidal, associadas a pequenas ondulações. Essas perturbações podem ser associadas à atividade escavatória de organismos, com preenchi- mento ativo durante seu deslocamento, em sedimentos semiconsolidados e recém-exumados no leito marinho. Entretanto, a preservação dessas estruturas inferiores é menos nítida, e essa interpretação não é conclusiva, uma vez que elas poderiam também ser interpretadas como pseudonódulos ou estruturas em bola-e-almofada e marcas de calha, associadas a estruturas de carga ou dobras convolutas, de origem abiótica (ver Collinson \& Thompson, 1989).

\section{DISCUSSÃO}

A gênese e significado de tais estruturas nas rochas do Quadrilátero Ferrífero levam à formulação imediata de três hipóteses:

\section{Evidências de vida macroscópica no Proterozóico}

A primeira hipótese parte do pressuposto que a origem das estruturas é de fato biogênica, bem como a idade das rochas é paleoproterozóica. Assim, os supostos icnofósseis
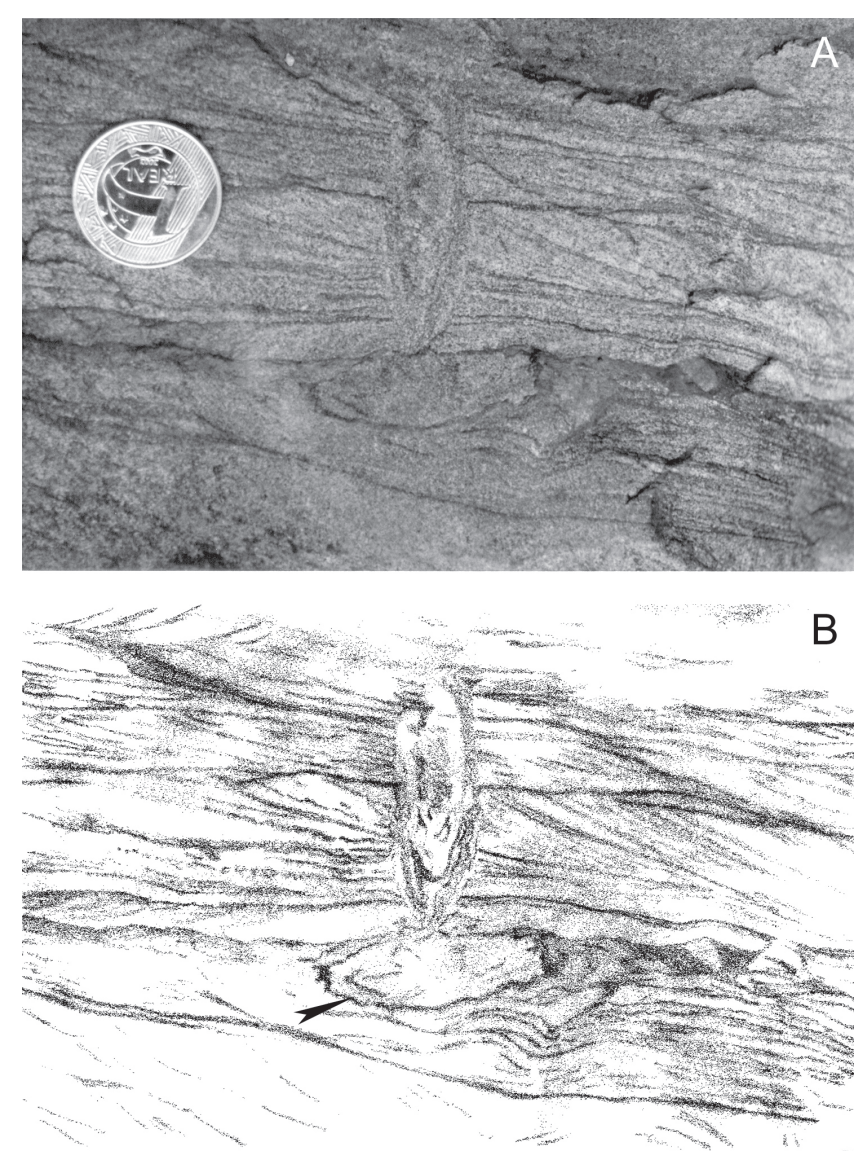

Figura 4. Fotografia de campo $(\mathbf{A})$ e desenho esquemático (B) de uma escavação semelhante a Arenicolites preservada em seção perpendicular ao acamamento. A seta aponta outras estruturas associadas, possivelmente um pseudonódulo acompanhado de pequenas dobras convolutas. Escala $=2,7 \mathrm{~cm}$ de diâmetro.

Figure 4. Field photography $(\mathbf{A})$ and schematic drawing (B) of an Arenicolites-like excavation, preserved in a section perpendicular to bedding plane. Arrow points to associated structures, possibly a "pseudo-nodule" with small convolute folds. Scale $=2.7 \mathrm{~cm}$ in diameter. 
da Formação Cercadinho seriam o mais antigo indício de vida multicelular e/ou macroscópica com mobilidade. Essa hipótese, entretanto, é incongruente com o registro fóssil global e com as teorias de origem dos metazoários.

Icnofósseis com idades semelhantes são raros e polêmicos. Hofmann (1967) descreveu estruturas que julgou como de origem orgânica em rochas de cerca de 2,2 Ga do Canadá, mas posteriormente reconsiderou essa interpretação (Hofmann, 1971). Outras ocorrências possíveis, embora isoladas e discutíveis, irão ocorrer apenas no Meso- a Neoproterozóico do Canadá, Namíbia e Índia (e.g., Arya \& Rao, 1979; Hofmann \& Aitken, 1979; Killick, 1983; Seilacher et al., 1998). Os icnofósseis apresentam um aumento em diversidade e abundância apenas próximo ao limite entre o Proterozóico e o Fanerozóico (Crimes, 1994; Jensen, 2003).

Poucos são os possíveis organismos macroscópicos conhecidos com idade similar à da Formação Cercadinho, e seu registro ainda é bastante discutido. Um exemplo recorrente é Grypania spiralis (Walcott) Walter, Oehler \& Oehler, 1990. Corresponde a filamentos septados, de largura entre 0,5 e 2,1 mm e atingindo vários centímetros de comprimento. A forma mais comum de preservação é espiralada, com um diâmetro máximo de 3,2 cm, mas pode se apresentar reta, curva, ou até mesmo formando um anel circular. Han \& Runnegar (1992) reportaram espécimes com 2,1 Ga, na Formação Ferrífera Negaunee, em Michigan, Estados Unidos.

As afinidades biológicas desse morfótipo são controversas. Originalmente, Grypania foi interpretado como uma trilha de metazoários, pertencente ao icnogênero Helminthoidichnites Fitch, 1850, mas também já foi considerado como um anelídeo, cianobactéria ou mesmo uma alga eucariótica megascópica (Kumar, 1995). A maior parte dos registros de organismos macroscópicos anteriores ao Neoproterozóico parecem ser relacionados com floras, como algas planctônicas. Mesmo que a ocorrência de formas espiraladas e retilíneas possa sugerir movimento, como ocorre com Grypania, essas feições também podem resultar da decomposição dos organismos, e não representar capacidade de escavação ativa de sedimentos.

As mais antigas e diversificadas faunas de fósseis de metazoários megascópicos são ediacarianas, presentes entre 542 e 575 Ma (Narbonne, 2005) e representadas predominantemente por criaturas de forma discóide (medusóides) ou pinulada. Nelas podem estar presentes formas ancestrais de cnidários, anelídeos e artrópodes (Glaessner, 1984), embora
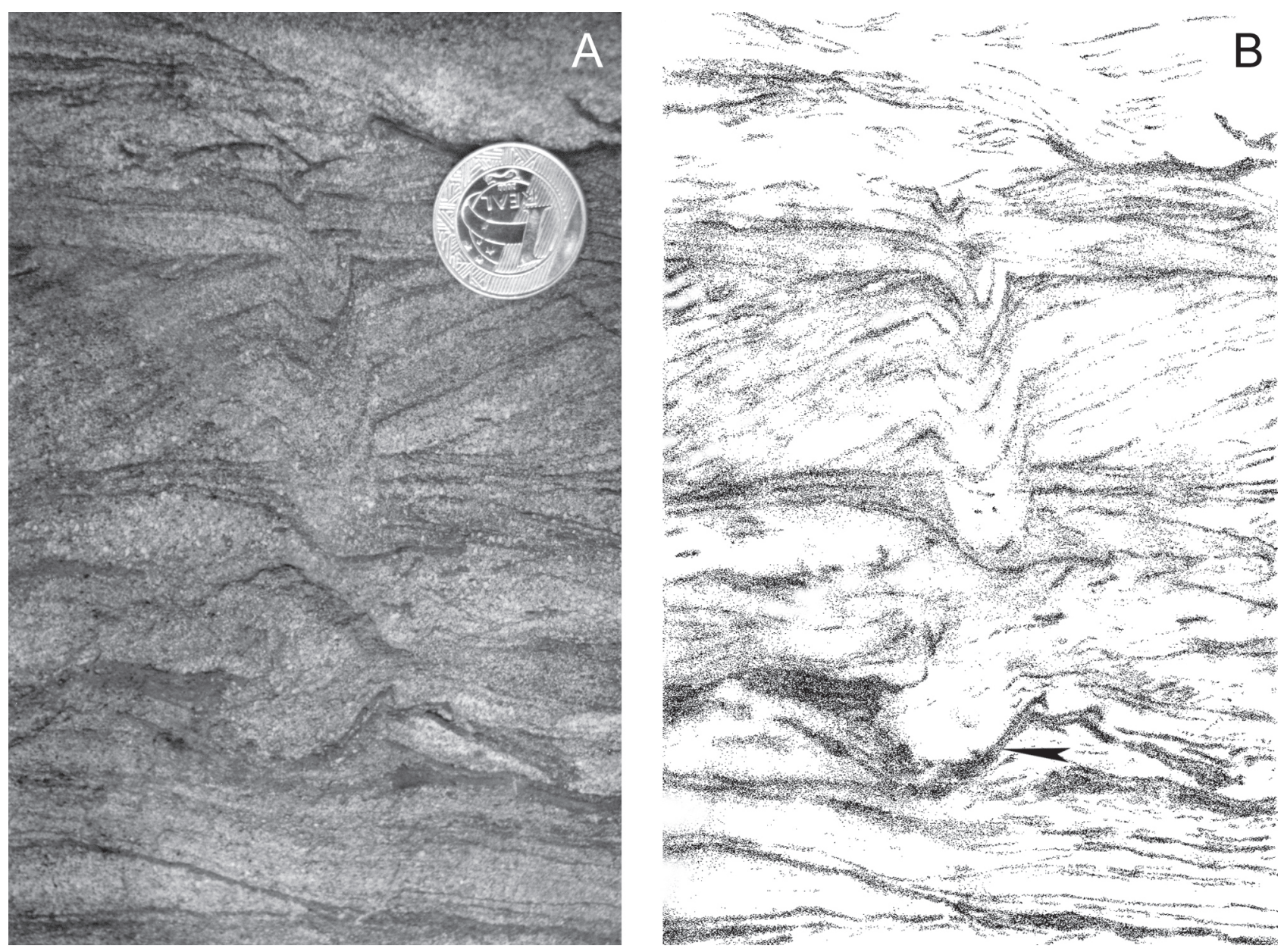

Figura 5. Fotografia de campo (A) e desenho esquemático (B) de uma estrutura de escape preservada em seção perpendicular ao acamamento. A seta aponta outra estrutura associada, possivelmente uma marca de calha. Escala $=2,7 \mathrm{~cm}$ de diâmetro.

Figure 5. Field photography (A) and schematic drawing (B) of an escape structure preserved in a section perpendicular to bedding plane. Arrow points to associated structure, maybe a gutter cast. Scale $=2.7 \mathrm{~cm}$ in diameter. 
essa interpretação seja criticada (e.g., Seilacher, 1992; Brasier \& Antcliffe, 2004). Apesar de não haverem muitos vestígios anteriores, certamente os metazoários se originaram anteriormente a essas faunas, e sua origem é relacionada ao declínio das comunidades de estromatólitos, a partir de $1 \mathrm{Ga}$, e intensificado entre 800 e $700 \mathrm{Ma}$ (Walter \& Heys, 1985). Seu surgimento deve ser condicionado também pela disponibilidade de oxigênio na Terra, embora haja evidências para um súbito aumento das pressões de $\mathrm{O}_{2}$ no intervalo entre 2,2 e 1,8 Ga (Knoll \& Holland, 1995).

\section{A idade da Formação Cercadinho}

A segunda hipótese surge como conseqüência natural das observações anteriores: as rochas que contêm as estruturas tidas como biogênicas teriam idade mais nova que a considerada anteriormente. A Formação Cercadinho (ou parte dela) e unidades sobrejacentes poderiam ser talvez cronocorrelatas ao Grupo Bambuí (de idade neoproterozóica, ver Babisnki et al., 1993b; Babinski, 2005), com um hiato de mais de 1,5 Ga entre essas unidades e o topo do Grupo Itabira.

Entretanto, existe uma grande variedade de empecilhos para esse cenário. Algumas limitações, por exemplo, são de ordem estratigráfica. O Grupo Itacolomi, que se sobrepõe ao Supergrupo Minas, é geralmente correlacionado com o Supergrupo Espinhaço, cuja deposição se inicia no final do Paleoproterozóico e se estende durante o Mesoproterozóico. Mas esse problema pode ser contornado, uma vez que o Grupo Itacolomi não tem exposição na serra do Curral e, portanto, nesse aspecto, parte das unidades mapeadas nessa área como Formação Cercadinho poderia representar um sistema mais jovem.

O Grupo Sabará representa uma unidade de difícil posicionamento estratigráfico, mas é geralmente considerado como topo do Supergrupo Minas. O padrão de idades para zircões detríticos desse grupo apresenta semelhanças com o do Grupo Itacolomi e Supergrupo Espinhaço (Machado et al., 1989, 1993; Machado \& Noce, 1993), sugerindo que as mesmas partes de embasamento estariam disponíveis como áreas-fonte para essas unidades. Ainda, Machado et al. $(1989,1992)$, baseados em datações $\mathrm{U} / \mathrm{Pb}$ de zircões detríticos, interpretaram a idade máxima de deposição dessa unidade em $2.125 \pm 4$ Ma, impondo-a como limite de deposição para as formações inferiores, incluindo a Formação Cercadinho.

Rochas carbonáticas das unidades estratigraficamente adjacentes à Formação Cercadinho, as formações Gandarela e Fecho do Funil, também foram datadas (Babinski et al., 1993a, 1995). As idades mínimas obtidas por isócronas $\mathrm{Pb} / \mathrm{Pb}$ $(2.420 \pm 19$ e $2.110 \pm 110 \mathrm{Ma}$, respectivamente) corroboram os dados anteriores de zircões detríticos, e restringem a deposição da Formação Cercadinho nesse intervalo. A Formação Gandarela é intimamente relacionada com as formações ferríferas, e sua idade é vinculada à correlação desses depósitos em diversos locais do mundo. Babisnki et al. (1993a) assumem uma idade de deposição máxima para a Formação Cauê em cerca de 2,5 Ga, concordante com as idades de outras formações ferríferas na África do Sul e Austrália.

Análises de isótopos estáveis das rochas carbonáticas do Quadrilátero Ferrífero (Sial et al., 2000) apresentam correlações que também são coerentes com as datações $\mathrm{Pb} / \mathrm{Pb}$. As rochas da Formação Fecho do Funil, especificamente, apresentaram dados compatíveis com a anomalia positiva de $\delta^{13} \mathrm{C}$ Lomagundi, típica no Paleoproterozóico. Entretanto, anomalias positivas de magnitude semelhante também ocorrem em diversos picos no período entre 500 e $750 \mathrm{Ma}$ (Hoffman et al., 1998).

Datações LA-ICPMS ${ }^{207} \mathrm{~Pb} /{ }^{206} \mathrm{~Pb}$ em zircões detríticos da própria Formação Cercadinho (Machado et al., 1996), de amostras do segmento oriental da serra do Curral, apresentaram idades similares às dos zircões do Grupo Caraça, que sugerem áreas-fonte similares, do Arqueano. Os dados para os grupos Sabará e Itacolomi apresentam padrões distintos, com uma contribuição de detritos derivados de terrenos formados durante o evento transamazônico. Esses dados também estão de acordo com uma idade paleoproterozóica para a Formação Cercadinho.

Veios pegmatíticos que cortam o Supergrupo Minas nunca foram datados, mas corpos similares no embasamento apresentaram idades $\mathrm{U} / \mathrm{Pb}$ em monazitas de 2,06 Ga (Noce, 1995). Datações de rochas que efetivamente cortam toda a sequiência foram provenientes de um dique máfico, localizado na região central da serra do Curral, e datado em 1,714 Ga (Silva et al., 1995).

Baseados nos dados $\mathrm{Rb} / \mathrm{Sr}$ para o metamorfismo das rochas do embasamento cristalino, alguns autores (e.g. Cordani et al., 1980) argumentam que a deposição do Supergrupo Minas necessariamente deve ter ocorrido antes do principal evento metamórfico, de idade transamazônica $(\sim 2,1 \mathrm{Ga})$, que afetou regionalmente o Quadrilátero Ferrífero. Muito embora as rochas arenáceas da Formação Cercadinho na serra dos Franceses apresentem estruturas sedimentares muito bem preservadas, a ocorrência de filitos deformados e rochas carbonáticas recristalizadas nas proximidades atestam o metamorfismo na região. Romano (1989), em estudo abrangendo a porção ocidental da serra do Curral, confirma metamorfismo na fácies xisto-verde, expresso no desenvolvimento de sericita, identificando ainda almandina em quartzitos da Formação Cercadinho. Segundo ele, não é possível identificar o evento brasiliano, sendo esse metamorfismo produto do evento transamazônico, e talvez tendo alguma influência de um evento mesoproterozóico (Uruaçuano).

\section{Origem abiótica: uma nova estrutura sedimentar?}

A terceira hipótese sobre o significado dessa ocorrência é que poderiam se tratar de estruturas sedimentares inorgânicas. A interpretação de processos geradores fica parcialmente prejudicada por se conhecerem as estruturas apenas em duas dimensões.

Descarta-se que as relações de base e topo das camadas onde as estruturas se encontram tenha sido equivocada, e que sejam perturbações ascendentes ao invés de representar colapso de material. Tais relações são atestadas pelas estratificações tangenciais e pela granodecrescência ascendente nos estratos onde são encontradas as estruturas, além de concordarem com a estratigrafia local. Por esses fatos, a disposição das estruturas as torna bem distintas de diversas feições abióticas de deformação sedimentar reconhecidas, geradas nor- 
malmente por fluxos liquefeitos, fluidização ou carga, como, por exemplo, as estruturas em chama, prato, pilar, vulcões de areia e diques clásticos (Pettijohn \& Potter, 1964; Lowe \& LoPiccolo, 1974; Allen, 1984; Fritz \& Moore, 1988; Collinson \& Thompson, 1989), todas geralmente ascendentes. De fato, se a fluidização tivesse sido um processo responsável pela geração das estruturas da Formação Cercadinho, seria esperado um número maior de estruturas semelhantes preservadas. Contudo, feições de fluidização reconhecíveis, assim como estratos maciços e estruturas de piping, não foram observadas em nenhuma camada no afloramento.

As estruturas também não devem ser conseqüência de feições de carga ou de choque sísmico, que poderiam gerar espaço para colapso, incluindo estruturas do tipo bola-e-almofada e marcas de calha (Pettijohn \& Potter, 1964, Allen, 1984; Fritz \& Moore, 1988; Collinson \& Thompson, 1989; Bhattacharya \& Bandyopadhyay, 1998), que não são registradas associadas a tubos colapsados na vertical. Escape de gás também pode, eventualmente, produzir estruturas de colapso de sedimento sobre as cavidades deixadas, mas essas são estruturas de muito menor porte (Allen, 1984; Fritz \& Moore, 1988). Por fim, a falta de continuidade vertical das estruturas nas camadas é também um impedimento para tentar explicá-las a partir de pequenos movimentos tectônicos, como microfalhamentos.

Embora, com exceção de icnofósseis, não tenha sido possível encontrar até o momento nada semelhante na literatura, poderíamos estar lidando com uma estrutura de gênese ainda desconhecida. A partir de experimentos de sedimentação simples, efetuados em laboratório, tentou-se reproduzir as estruturas, simulando processos que poderiam ocorrer de forma abiótica, ou que não dependessem de organismos com mobilidade, podendo envolver uma célula macroscópica, escape de gás ou ainda a formação de cavidades revestidas por lâminas peletoidais, posteriormente rompidas. Foi utilizado um aquário com $40 \mathrm{~cm}$ de comprimento, $20 \mathrm{~cm}$ de altura e $3 \mathrm{~cm}$ de largura, com água até a borda. Nele foram depositadas camadas de areia e argila, que por suspensão formaram estratos aproximadamente plano-paralelos. Estruturas levemente semelhantes à primeira descrita (Figura 6A) foram geradas apenas com escavações ativas do sedimento, abrindo-se espaço na areia com uma chapa metálica. Entre as tentativas para se gerar a segunda estrutura, foi posicionada na base do aquário uma pequena bolsa plástica, preenchida de gás, que foi rompida por uma haste metálica que atravessava o sedimento até a superfície. O colapso de sedimento só foi obtido quando a haste era removida, o que permitia que o gás escapasse, e as estruturas geradas não possuíam paredes bem marcadas, com a laminação se assemelhando mais a uma curva senoidal, sem quebras em chevron (Figura 6B). Esses experimentos, embora preliminares, sugerem a dificuldade de se gerar estruturas semelhantes de forma abiótica.

\section{CONSIDERAÇÕES FINAIS}

Aparentemente, a hipótese de que as estruturas descobertas na Formação Cercadinho se tratem de feições sedimentares abióticas parece ser a mais provável. Essa situa- ção, contudo, resulta muito mais dos empecilhos apresentados às outras proposições que de argumentos próprios. Nenhuma das hipóteses levantadas pode ser descartada definitivamente sem recorrer a considerações preconcebidas, e no caso de tentar se provar que as estruturas possuem origem abiótica, novos mecanismos geradores e processos precisam ser propostos e testados.

A proposição de que parte do Supergrupo Minas teria idade mais jovem que a atualmente considerada ainda pode ser mais detalhadamente averiguada, incluindo novas datações. Muitos dados deverão ser revistos e amostragens efetuadas, em especial ao redor do segmento ocidental da serra do Curral. Algumas das análises efetuadas anteriormente, feitas em outros segmentos do Quadrilátero Ferrífero, foram ampliadas para toda a região, em uma simplificação que pode esconder relações temporais muito mais complexas.

Por outro lado, abre-se um novo leque de considerações a serem feitas, se confirmada a idade e a origem biótica dessas estruturas. Elas teriam sido produzidas por organismos ainda não identificados no registro sedimentar, e tentar concebê-los é ainda apenas matéria de especulações.

Embora muitos estudos geológicos tenham sido efetuados no Quadrilátero Ferrífero, provavelmente os mapeamentos mais detalhados se concentraram nos depósitos de minério, dando menor ênfase às demais unidades do Supergrupo Minas. Além disso, pela idade estimada das rochas da Formação Cercadinho, os estudos realizados nesses depósitos provavelmente nunca tiveram por objetivo buscar evidências macroscópicas de vida, e mesmo estruturas semelhantes podem ter passado desapercebidas. É fundamental, pois, encontrar novas ocorrências dessas estruturas na Formação Cercadinho, para uma análise mais acurada sobre sua gênese.
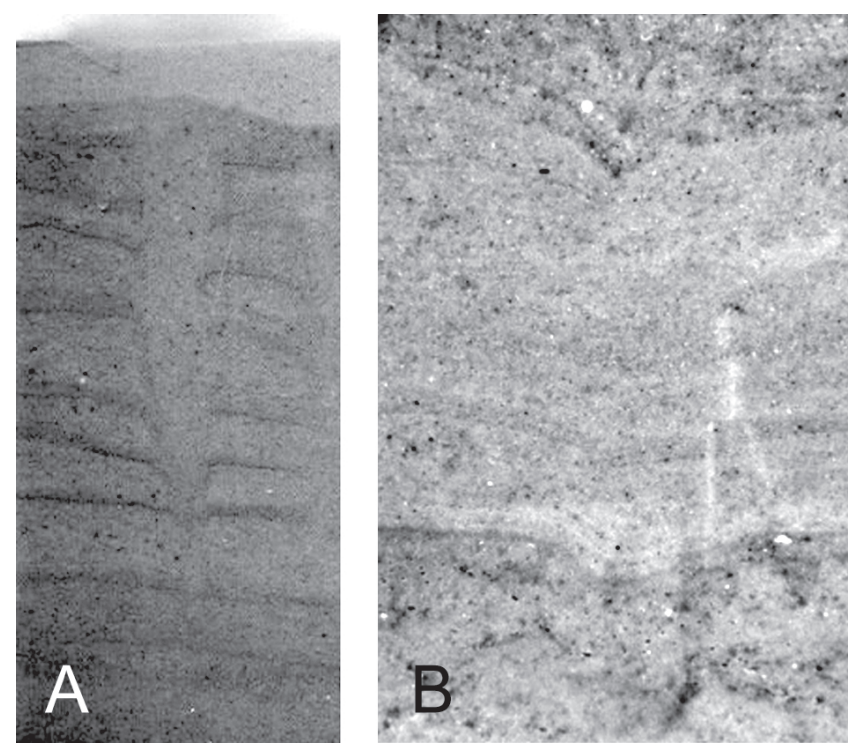

Figura 6. Exemplos de estruturas obtidas em experimentos de sedimentação, efetuados em laboratório: estrutura provocada por escavação ativa de sedimento (A) e colapso de sedimentos induzido por escape de gás (B).

Figure 6. Examples of sedimentary structures obtained in laboratory experiments: structure produced by active burrowing $(\mathbf{A})$ and collapse of sediments induced by gas scape (B). 


\section{AGRADECIMENTOS}

As estruturas foram descobertas durante o mapeamento geológico da serra dos Franceses, trabalho realizado para a Ferteco Mineração S.A., Companhia Vale do Rio Doce, e desenvolvido em parceria com a Universidade Federal de Minas Gerais. O autor sênior é grato ao CNPq por concessão de bolsa. Agradecemos a Thomas R. Fairchild (IGc/USP), Antônio Carlos S. Fernandes (MN/UFRJ), Leonardo Borghi (IGEO/UFRJ), Renata G. Netto (UNISINOS), Eduardo A. M. Koutsoukos (Petrobrás/CENPES), Carlos Maurício Noce (IGC/UFMG), Antônio Wilson Romano (IGC/UFMG), Antônio Carlos Pedrosa Soares (IGC/UFMG), Michael Holz (IG/ UFRGS) e dois revisores anônimos por sugestões e críticas. Júlio Seara e Marcelo Rossi (Ferteco S.A.) nos apoiaram em campo. Finalmente, agradecemos a Rafael Emílio Lopes, que auxiliou na construção do aquário utilizado nos experimentos. Este trabalho foi uma contribuição ao XIX Congresso Brasileiro de Paleontologia/VI Congresso Latino-americano de Paleontologia, ocorrido em Aracajú, SE, em agosto de 2005.

\section{REFERÊNCIAS}

Abreu, J.C., Hessel, M.H.R. \& Costa, M.G.F. (eds.) 1993. Icnofósseis \& icnofácies em testemunhos. Rio de Janeiro, Petrobrás/CENPES, 116 p. (Documento interno, inédito).

Alkmim, F.F. \& Marshak, S. 1998. Transamazonian orogeny in the southern São Francisco Craton region, Brazil: evidence for Paleoproterozoic collision and collapse in the Quadrilátero Ferrífero. Precambrian Research, 90(1-4):29-58.

Allen, J.R.L. 1984. Sedimentary structures: their character and physical basis. $2^{\mathrm{a}}$ ed., Amsterdam, Elsevier Science Publishing, 593 p. (Developments in Sedimentology, 30).

Arya, B.C. \& Rao, C.N. 1979. Bioturbation structures from the Middle Proterozoic Narji Formation, Kurnool Group, Andhra Pradesh, India. Sedimentary Geology, 22:127-134.

Babinski, M. 2005. A idade do Supergrupo São Francisco: revisão e implicações nas glaciações neoproterozóicas. In: SIMPÓSIO SOBRE O CRÁTON DO SÃO FRANCISCO, 3, 2005. Anais, Salvador, SBG BA-SE/SGM, p. 135-138.

Babinski, M.; Chemale Jr., F. \& Van Schmus, W.R. 1993a. A idade das formações ferríferas bandadas do Supergrupo Minas e sua correlação com aquelas da África do Sul e Austrália. In: SIMPÓSIO SOBRE O CRÁTON DO SÃO FRANCISCO, 2, 1993. Anais, Salvador, SBG BA-SE/SGM, p. 152-153.

Babinski, M.; Chemale Jr., F. \& Van Schmus, W.R. 1995. The Pb/ $\mathrm{Pb}$ age of the Minas Supergroup carbonate rocks, Quadrilátero Ferrífero, Brazil. Precambrian Research, 72(3-4):235-245.

Babinski, M.; Van Schmus, W.R.; Chemale Jr., F. \& Kawashita, K. 1993b. Evolução geológica da porção sul da bacia do São Francisco baseada na geoquímica isotópica de $\mathrm{Pb}$ em rochas carbonáticas. In: SIMPÓSIO SOBRE O CRÁTON DO SÃO FRANCISCO, 2, 1993. Anais, Salvador, SBG BA-SE/SGM, p. 182-185.

Bhattacharya, H.N. \& Bandyopadhyay, S. 1998. Seismites in a Proterozoic tidal succession, Singhbhum, Bihar, India. Sedimentary Geology, 119:239-252.

Brasier, M. \& Antcliffe, J. 2004. Decoding the Ediacaran enigma. Science, 305:1115-1117.
Bromley, R.G. 1996. Trace fossils: biology, taphonomy and applications. $2^{\mathrm{a}}$ ed., London, Chapman \& Hall, 361 p.

Caby, R. 2000. Neoproterozoic tectonometamorphic imprint in the Quadrilátero Ferrífero, São Francisco Craton (SE Brazil). In: INTERNATIONAL GEOLOGICAL CONGRESS, 31, 2000. Abstracts Volume, Rio de Janeiro, CPRM, 1 CD-ROM.

Cloud, P.; Gustafson, L.B. \& Watson, J.A.L. 1980. The works of living social insects as pseudofossils and the age of the oldest known Metazoa. Science, 210:1013-1015.

Collinson, J.D. \& Thompson, D.B. 1989. Sedimentary structures. $2^{\mathrm{a}}$ ed., London, Unwin Hyman, 207 p.

Cordani, U.G.; Kawashita, K.; Müller, G.; Quade, H.; Reimer, V. \& Roeser, H. 1980. Interpretação tectônica e petrológica de dados geocronológicos do embasamento na borda sudeste do Quadrilátero Ferrífero/MG. Anais da Academia Brasileira de Ciências, 52(4):785-799.

Crimes, T.P. 1994. The period of early evolutionary failure and the dawn of evolutionary success: the record of biotic changes across the Precambrian-Cambrian boundary. In: S.K. Donovan (ed.) The paleobiology of trace fossils, The Johns Hopkins University Press, p. 105-133.

Dorr, J.V.N., II. 1969. Physiographic, stratigraphic and structural development of the Quadrilátero Ferrifero, Minas Gerais, Brazil. Washington, United States Geological Survey, 110 p. (Professional Paper 641A).

Fedonkin, M.A. 1990. Precambrian metazoans. In: D.E.G. Briggs \& P.R. Crowther (eds.) Palaeobiology: a synthesis. Blackwell Science, p. 17-24.

Fernandes, A.C.S., Borghi, L., Carvalho, I.S. \& Abreu, C.J. 2002. Guia dos icnofósseis de invertebrados do Brasil. Rio de Janeiro, Interciência, 260 p.

Fernandes, A.C.S. \& Carvalho, I.S. 2006. Invertebrate ichnofossils from the Adamantina Formation (Bauru Basin, Late Cretaceous), Brazil. Revista Brasileira de Paleontologia, 9(2):211-220.

Fritz, W.J. \& Moore, J.N. 1988. Basics of physical stratigraphy and sedimentology. New York, John Wiley \& Sons, 371 p.

Fürsich, F.T. 1974. Trace fossils as environmental indicators in the Corrallian of England and Normandy. Lethaia, 8:151-172.

Glaessner, M.F. 1984. The dawn of animal life. Cambridge, Cambridge University Press, 244 p.

Han, T.-M. \& Runnegar, B. 1992. Megascopic eukaryotic algae from 2.1-billion-year-old Negaunee Iron-Formation, Michigan. Science, 257(5067):232-235.

Hoffman, P.F.; Kaufman, A.J. \& Halverson, G.P. 1998. Comings and goings of global glaciations on a Neoproterozoic tropical platform in Namibia. GSA Today, 8(5):1-10.

Hofmann, H.J. 1967. Precambrian fossils (?) near Elliot Lake, Ontario. Science, 156:500-504.

Hofmann, H.J. 1971. Precambrian fossils, pseudofossils, and problematica in Canada. Geological Survey of Canada Bulletin, 189:1-146.

Hofmann, H.J. \& Aitken, J.D. 1979. Precambrian biota from the Little Dal Group, Mackenzie Mountains, northwestern Canada. Canadian Journal of Earth Sciences, 16:150-166.

Jensen, S. 2003. The Proterozoic and Earliest Cambrian trace fossil record: patterns, problems and perspectives. Integrative and Comparative Biology, 43:219-228.

Killick, A.M. 1983. A preliminary account of the geology of the Kamtsas Formation of the Damara sequence, eastern Gobadis district, south west Africa/Namibia. Transactions of the Geological Society of South Africa, 86:11-18. 
Knoll, A.H. \& Holland, H.D. 1995. Oxygen and Proterozoic evolution: an update. In: National Research Council. Effects of past global change on life. National Academy Press, p. 21-33 (Studies in Geophysics).

Kumar, S. 1995. Megafossils from the Mesoproterozoic Rohtas Formation (the Vindhyan Supergroup), Katni area, central India. Precambrian Research, 72(3-4):171-184.

Lowe, D.R. \& LoPiccolo, R.D. 1974. The characteristics and origins of dish and pillar structures. Journal of Sedimentary Petrology, 44(2):484-501.

Machado, N. \& Noce, C.M. 1993. Evolução do setor sul do Cráton do São Francisco entre 3,1 e 0,5 Ga baseada em geocronologia U$\mathrm{Pb}$. In: SIMPÓSIO SOBRE O CRÁTON DO SÃO FRANCISCO, 2, 1993. Anais, Salvador, SBG BA-SE/SGM, p. 100-102.

Machado, N.; Noce, C.M. \& Feng, R. 1993. Idades ${ }^{207} \mathrm{~Pb} /{ }^{206} \mathrm{~Pb}$ de zircões detríticos de rochas metassedimentares da região do Quadrilátero Ferrífero, sul do Cráton do São Francisco: Considerações sobre áreas-fonte e idades de sedimentação. In: SIMPÓSIO SOBRE O CRÁTON DO SÃO FRANCISCO, 2 , 1993. Anais, Salvador, SBG BA-SE/SGM, p. 149-151.

Machado, N.; Noce, C.M.; Ladeira, E.A. \& Belo de Oliveira, O. 1992. U-Pb geocronology of Archean magmatism and Proterozoic metamorphism in the Quadrilátero Ferrífero, southern São Francisco craton, Brazil. Geological Society of America Bulletin, 104(9):1221-1227.

Machado, N.; Schrank, A.; Abreu, F.R.; Knauer, L.G. \& Almeida Abreu, P.A. 1989. Resultados preliminares da geocronologia $\mathrm{U} / \mathrm{Pb}$ na Serra do Espinhaço meridional. In: SIMPÓSIO DE GEOLOGIA DE MINAS GERAIS, 5, 1989. Anais, Belo Horizonte, SBG-MG, p. 171-174. (Boletim 10).

Machado, N.; Schrank, A.; Noce, C.M. \& Gauthier, G. 1996. Ages of detrital zircon from Archean-Paleoproterozoic sequences: implications for greenstone belt setting and evolution of a Transamazonian foreland basin in Quadrilátero Ferrífero, southeast Brazil. Earth and Planetary Science Letters, 141(14):259-276.

Martinsson, A. 1970. Toponomy of trace fossils. In: T.P. Crimes \& J.C. Harper (eds.) Trace fossils. Geological Journal Special Issue, 3:323-330.

McIlroy, D. \& Garton, M. 1994. A worm's eye view of the Early Palaeozoic sea floor. Geology Today, 20(6):224-230.

Narbonne, G.M. 2005. The Ediacara Biota: Neoproterozoic origin of animals and their ecosystems. Annual Review of Earth and Planetary Sciences, 33:421-442.

Netto, R.G. 2002. Paleoicnologia do Rio Grande do Sul. In: M. Holz \& L.F. De Ros (eds.) Paleontologia do Rio Grande do Sul. CIGO/UFRGS, p. 25-43.
Noce, C.M. 1995. Geocronologia dos eventos magmáticos, sedimentares e metamórficos na região do Quadrilátero Ferrífero, Minas Gerais. Programa de Pós-graduação em Geociências, Universidade de São Paulo, Tese de Doutorado, $78 \mathrm{p}$.

Peterson, K.J. \& Butterfield, N.J. 2005. Origin of the Eumetazoa: testing ecological predictions of molecular clocks against the Proterozoic fossil record. Proceedings of the National Academy of Sciences, 102(27):9547-9552.

Pettijohn, F.J. \& Potter, P.E. 1964. Atlas and glossary of primary sedimentary structures. Berlin, Springer, $370 \mathrm{p}$.

Romano, A.W. 1989. Evolution tectonique de la region nord-ouest du Quadrilatère Ferrifère - Minas Gerais - Brésil (Geochronologie du socle - aspects geochimisques et petrographiques des Supergroupes Rio das Velhas et Minas). U. E. R. Geosciences et materiaux, Université de Nancy I, Tese de Doutorado, $259 \mathrm{p}$.

Seilacher, A. 1992. Vendobionta and Psammocorallia: lost constructions of Precambrian evolution. Journal of the Geological Society of London, 149:607-613.

Seilacher, A.; Bose, P.K. \& Pflüger, F. 1998. Triploblastic animals more than 1 billion years ago: trace fossil evidence from India. Science, 282:80-83.

Sial, A.L.; Ferreira, V.P.; Almeida, A.R.; Romano, A.W.; Parente, C.V.; Dacosta, M.L. \& Santos, V.H. 2000. Carbon isotope fluctuations in Precambrian carbonate sequences of several localities in Brazil. Anais da Academia Brasileira de Ciências, 72(4):539-558.

Silva, A.M.; Chemale, F., Jr. \& Heaman, L. 1995. The Ibirité gabbro and the Borrachudo granite - the rift-related magmatism of Mesoproterozoic age in the Quadrilátero Ferrífero (MG). In: SIMPÓSIO DE GEOLOGIA DE MINAS GERAIS, 8, 1995. Anais, Diamantina, Boletim da Sociedade Brasileira de Geologia - Núcleo Minas Gerais, 13:89-90.

Silva, L.C.; Armstrong, R.; Noce, C.M.; Carneiro, M.A.; Pimentel, M.; Pedrosa Soares, A.C.; Leite, C.A.; Vieira, V.S.; Silva, M.A.; Paes, V.J.C. \& Cardoso Filho, J.M. 2002. Reavaliação da evolução geológica em terrenos précambrianos brasileiros com base em novos dados U-Pb SHRIMP. Parte II: Orógeno Araçuaí, Cinturão Mineiro e Cráton São Francisco Meridional. Revista Brasileira de Geociências, 32(4):513-528.

Walter, M.R. \& Heys, G.R. 1985. Links between the rise of the Metazoa and the decline of stromatolites. Precambrian Research, 29(1-3):149-174.

Received in October, 2005; accepted in October, 2006 